\title{
Gold Catalysis: Recent Developments and Future Trends
}

\author{
Cristina Nevado*
}

\begin{abstract}
The field of homogeneous gold catalysis has developed exponentially over the past ten years. Even if the array of gold-mediated transformations is extremely broad, a common feature stems from the ability of gold to activate unsaturated moieties due to the strong relativistic effects governing its coordination behavior. Starting with a short historical perspective, this review compiles the recent advances in two fundamental areas: first, the rearrangement of propargylic carboxylates and second, ring-expansion processes, both topics of interest in our research group at the Organic Chemistry Institute of the University of Zurich.
\end{abstract}

Keywords: Homogeneous catalysis · Gold · Propargylic carboxylates · Ring expansions

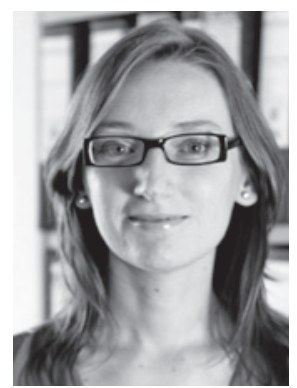

Cristina Nevado was born in Madrid in 1977. She studied chemistry at the Autónoma University of Madrid graduating in 2000. In October 2004 she received her $\mathrm{PhD}$ in organic chemistry at the same university working with Prof. Antonio M. Echavarren in the cyclization of 1,6-enynes catalyzed by late transition metals. In December 2004 she joined the lab of Prof. Alois Fürstner at the Max-Planck-Institut für Kohlenforschung (Germany) working on the total synthesis of bioactive marine macrolides. Since May 2007 she is Assistant Professor at the Organic Chemistry Institute of the University of Zürich.

${ }^{\star}$ Correspondence: Prof. Dr. C. Nevado

University of Zurich

Organic Chemistry Institute

Winterthurerstrasse 190

$\mathrm{CH}-8057$ Zürich

Tel.: +41446353945

Fax: + 41446356812

E-mail: nevado@oci.uzh.ch

(1935)<smiles>c1ccc2ccccc2c1</smiles><smiles>CC(C)(C)C</smiles><smiles>Clc1c(Cl)c(Cl)c2c(Cl)c(Cl)c(Cl)c(Cl)c2c1Cl</smiles><smiles>CC(C)=CC(C)C</smiles>

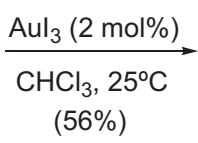<smiles>CC=CC=C(C)C</smiles>

3

(1986)

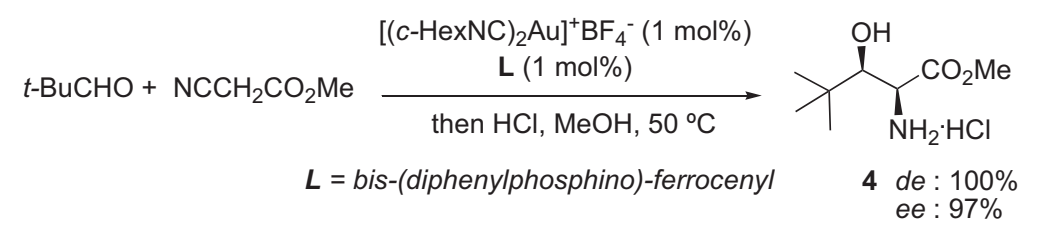

Scheme 1.

\section{Introduction}

'twere absurd to think that nature in the earth bred gold perfect in the instant; something went before [..]

Nature doth first beget the imperfect, then proceeds she to the perfect'

'The Alchemist' by Ben Jonson, 17th Century

The histories of chemistry and gold are intimately connected; at least if we assume that before 'chemistry' was 'alchemy'. ${ }^{[1]}$ From the Arabic al-kimia, 'the art of transformation' (the sacred art, the occult science, the art of Hermes), alchemy set up its highest goal at the transmutation of common metals into gold (chrysopoeia). ${ }^{[2]}$ In fact, alchemists were convinced metals were present in nature just as precursors of gold, as gold was considered to be the most perfect metal and nature always strives for perfection. In contrast to silver, copper or iron, gold could not be damaged nor transformed in the presence of acids, sulphur, or any other known entity. Maybe streamlining this belief, gold has drifted through history as a noble metal: an attractive ornamentation material, a currency of high value but an inert element, a 'dead entity' in terms of chemical reactivity. ${ }^{[3]}$ One among many other paradoxes in the development of chemistry, catalysis using gold(I) and gold(III) complexes has emerged in the past ten years with an unparalleled and unforeseeable power giving rise to the so-called 'gold-rush' era.

It is difficult to precisely assign the first transformations using catalytic amounts of gold (Scheme 1). We find a seminal contribution in the perchlorination of naphthalene (1) with $\mathrm{AuCl}_{3}$ or $\mathrm{AuCl}$ by Schwemberger and Gordon back in 1935. ${ }^{[4]}$ Almost forty years later, in 1972, gold was still considered to possess low reactivity, thus the investigation focused on highly reac- 
tive substrates such as bicyclo[1.1.0]butane (2), which isomerized to 2,5-dimethyl2,4-hexadiene (3) in the presence of gold salts. ${ }^{[5]}$ Another key contribution stemmed from the work of Ito and co-workers in 1986 with the synthesis of optically active $\beta$-hydroxyamino acid derivatives (4) from aldehydes and isocyanoacetates using $\left[\mathrm{Au}(\mathrm{c}-\mathrm{HexNC})_{2}\right]^{+} \mathrm{BF}_{4}^{-}$and chiral ferrocenyl ligands. ${ }^{6]}$ In parallel, heterogeneous and homogeneous Au-catalyzed reactions involving redox processes were developed but will not be further discussed here since review articles have been recently published in CHIMIA on these particular topics. ${ }^{[7]}$

Nowadays, the broadest and maybe most successful area in gold homogeneous catalysis stems from the ability of gold to coordinate, and thus activate, unsaturated moieties due to the strong relativistic effects governing its coordination behavior. ${ }^{[8]}$ Both gold(I) and gold(III) complexes can activate carbon-carbon double and triple bonds triggering an extensive palette of reactions. ${ }^{9]}$ Especially broad is the array of transformations derived from $\pi$-activated alkynes, which include among others: nucleophilic attack of alcohols, amines, alkenes, etc..., formation of vinylidene intermediates, push-pull reactivity, cycloadditions, cycloisomerizations, ring skeletal rearrangements, etc... Since each of these topics has already been extensively reviewed, ${ }^{[10]}$ this article will mostly focus on the evolution and most recent developments on carboxylate migrations and ring expansions, two major interests in our research group at the Organic Chemistry Institute of the University of Zurich.

Before closing this introductory section, one might wonder why among all metals, catalysis with gold has developed exponentially over the past decade. In addition to its rich reactivity, several advantages in the use of gold can be easily recognized: whilst still expensive, the price of gold is comparable to other noble metals such as palladium, platinum or rhodium, and currently lower than iridium. Furthermore, the catalyst can be recovered at the end of the reaction in most cases, since no redox chemistry is associated with it. ${ }^{[7]}$ In addition, no exhaustive inert atmosphere is required for the reactions to proceed efficiently, catalysts are air-stable, easy to handle, and offer high functional-group tolerance.

However, while much progress has been made in this field in recent years, important work is still ahead of us. First, our knowledge about the reaction mechanisms and key intermediates in these transformations is still scarce. ${ }^{[11]}$ Second, the limited capacity for rational design of new catalytic complexes and/or transformations still

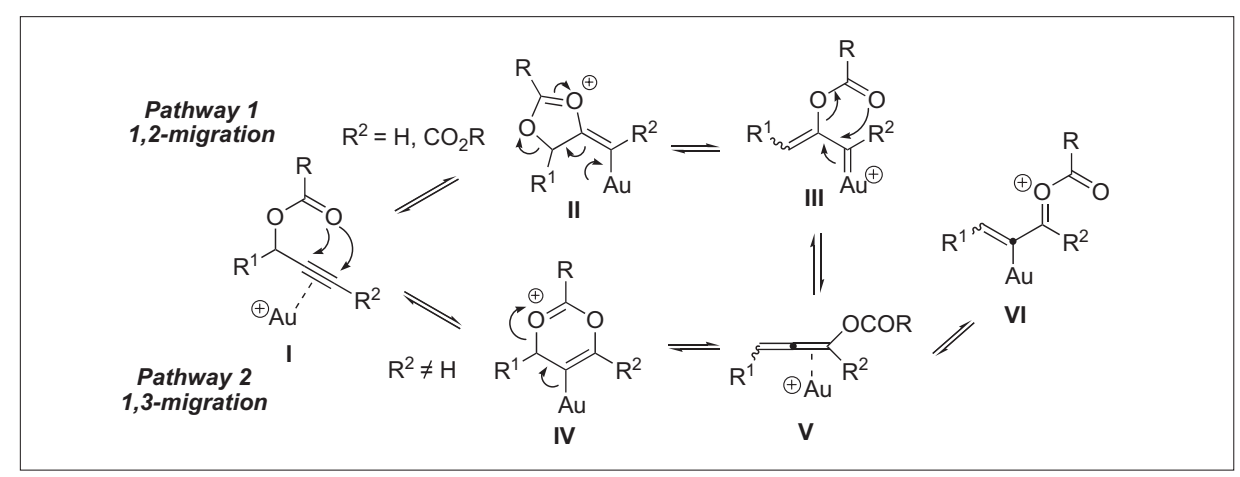

Scheme 2.

hinders the application of gold-catalyzed reactions in synthesis, an underdeveloped field compared to pure methodological work. ${ }^{[12]}$

\section{Rearrangement of Propargyl Carboxylates}

\subsection{General Considerations}

A common remark from 'non-aurophilic chemists' is that, due to the overwhelming number of publications, getting a 'general view' on gold chemistry is extremely challenging. Thus, hoping to make the forthcoming discussion more appealing, I will start this section by disclosing the conclusions and then go through the key examples that helped to define such reactivity trends.

Upon coordination to the alkyne, gold can efficiently activate propargyl carboxylates (I) towards 1,2-acyloxy migration and/or [3,3]-sigmatropic acyloxy rearrangement (Scheme 2). ${ }^{[13]}$ These two competitive processes seem to be mechanistically related: 1,2-migration proceeds via metal carbene III (pathway 1), whereas [3,3]-sigmatropic rearrangement proceeds via allenyl acetate $(\mathbf{V})$ in a single process or stepwise by a second acetate migration from III (pathway 2). ${ }^{[14]}$ Allenyl acetates $\mathbf{V}$ can be further activated in the presence of the gold catalyst to give VI, triggering an extensive palette of transformations. It is widely accepted that terminal or electron-poor alkynes react via the 1,2-,[15] whereas internal alkynes prefer the 1,3-migration pathway, ${ }^{[16]}$ although we will see several exceptions to this generalization.

\subsection{1,2-Acyloxy Migration}

The first examples reported on the rearrangement of propargyl acetates have Swiss roots. Günther Ohloff, working in the development of fragrance molecules at Firmenich (Geneva), back in 1976, reported the cyclization of dehydrolinalyl acetate mediated by $\mathrm{Zn}$-salts. ${ }^{[17]}$ Less than ten years later, Valentin Rautenstrauch,

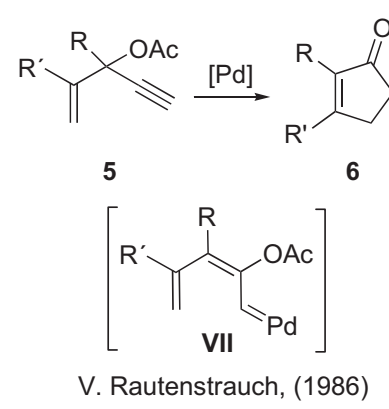

Scheme 3 .

also a chemist from Firmenich, published a related Pd-catalyzed cyclization of 1-ethynyl-2-propenyl acetates (5) to give 2-cyclopentenones (6, Scheme 3). ${ }^{[18]}$ Although lacking an in-depth mechanistic study, the formation of a Pd-carbene intermediate was postulated already at that time (VII). Work from Ohe and Uemura with ruthenium, ${ }^{[19]}$ and Malacria with platinum $^{[20]}$ re-opened the interest in this class of transformations at the beginning of this decade.

Multiple gold-catalyzed propargyl acyloxy rearrangements have been disclosed ever since validating the proposed reaction intermediates (Scheme 4). Toste and co-workers have been able to intercept the putative carbene intermediate generated after pivaloate migration in 7 by oxidation with diphenyl sulfoxide to give aldehyde 8. ${ }^{[21]}$ A second indirect proof for the intermediacy of III was provided with the gold-catalyzed formation of vinyl cyclopropanes (10) from propargyl acetates and olefins. ${ }^{[22]}$ As expected from a planar intermediate, a lack of chirality transfer in the reaction of enantiomerically enriched propargyl acetate 9 was observed. Recently, alkylidenes such as III have been exploited in several $[4 \mathrm{C}+3 \mathrm{C}]$ and $[3 \mathrm{C}+3 \mathrm{C}]$ cycloaddition reactions with 1,3-dipoles such as azomethine imine $\mathbf{1 2}$ in analogy to classical [3+2] cycloaddition chemistry. ${ }^{[23]}$

However, for intramolecular processes where an additional olefin is present in the starting material, a more complex mecha- 


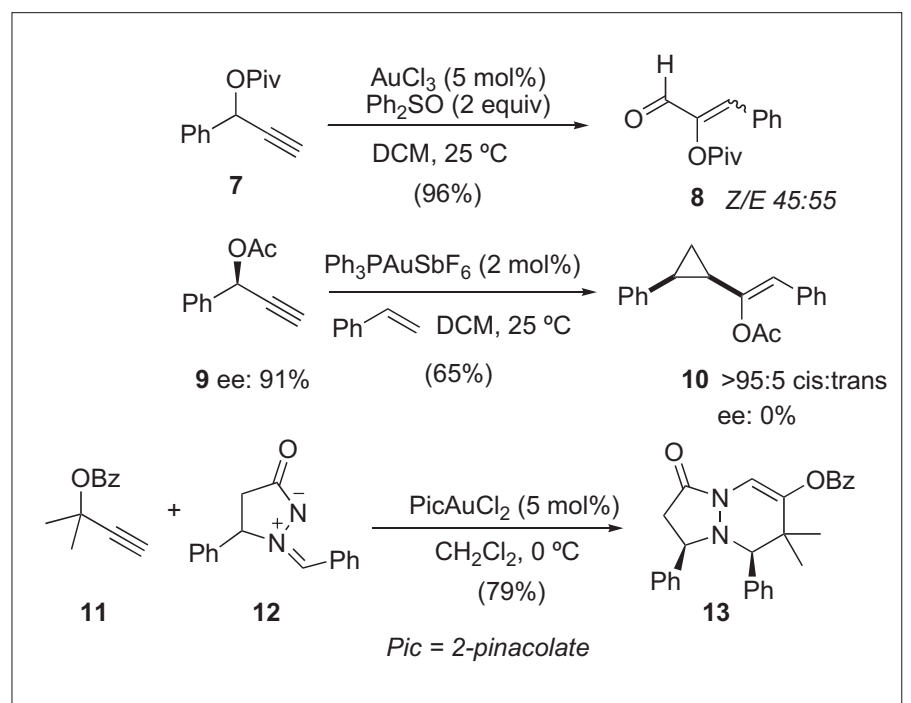

Scheme 4.

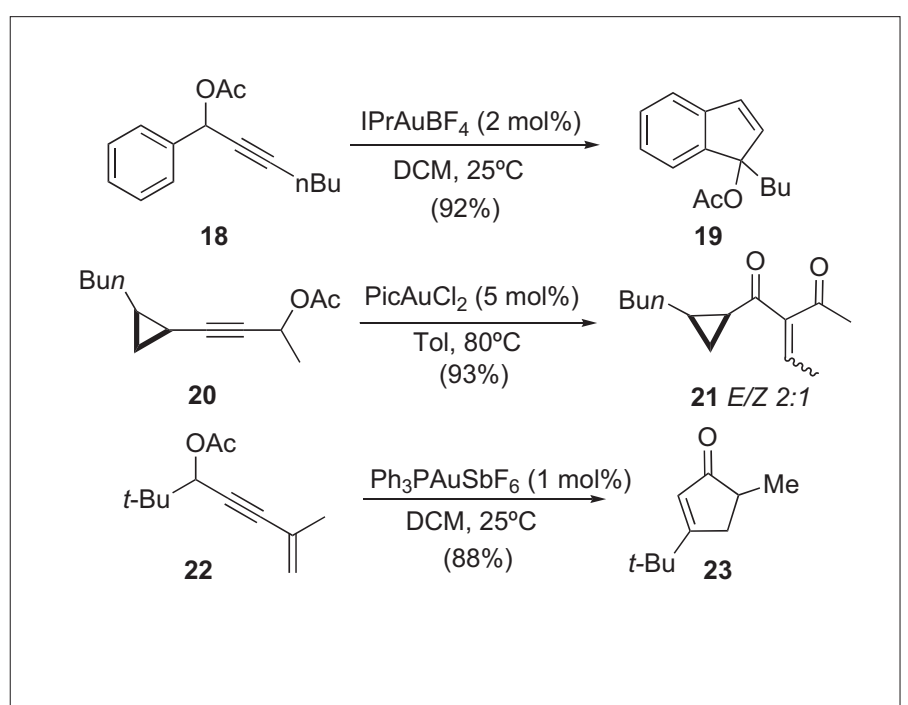

Scheme 6.

observed that the acetate moiety can undergo a fission process delivering $\alpha$-ylidene- $\beta$-diketones (21) in excellent yields (Scheme 6). ${ }^{[27]}$ In this case, a $\mathrm{Au}(\mathrm{III})$ catalyst stabilized by a 2-pinacolate ligand provided the best yields and selectivities. As in the case of 1,2-acyloxy migration pathways, the presence of an alkene in the starting material can trigger interesting transformations. Thus, substrates as $\mathbf{2 2}$ were transformed into the corresponding cyclopentenones (23) via complexes $\mathbf{V}$ and VI through a Nazarov-type electrocyclization. ${ }^{[28]}$

\subsection{Exceptions to the 1,2- vs.}

\section{1,3-Acyloxy Migration Pathways}

As mentioned above, the [3,3]-rearrangement and the 1,2-acyloxy migration of propargylic carboxylates can be considered competitive pathways, differing in the 5-exo vs. 6-endo-dig mode of the nucleophilic attack of the carbonyl group onto the alkyne. In fact, according to computational studies, both pathways seem to be interconnected. ${ }^{[14]}$ Factors such as sterics and electronics of the substituents at either end of the alkyne can influence the reaction outcome. Thus, the group of Zhang has recently reported a gold-catalyzed synthesis of (1Z,3E)-2-pivaloxy1,3-dienes (25), which proceeds via the 1,2-migration path on internal propargylic pivalates (24, Scheme 7). ${ }^{[29]}$ Key for the success in this transformation is the use of bulky migrating groups and catalysts (Piv and IPrAuNTf respectively), but also the presence of an hydrogen atom at the propargylic position so that upon 1,2-migration of the ester, $\beta$-hydride elimination can occur avoiding the formation of allenyl acetates $\mathbf{V}$.

The stereocontrolled synthesis of 1,3-dienes has an important synthetic potential since such motives are present in a large number of natural products with in- the propargylic position onto the newly formed stereocenters in the above-mentioned processes (Scheme 5). phile, the allenyl intermediates can generate vinyl-gold complexes VI (Scheme 2). In the case of substrate $\mathbf{2 0}$, Zhang 


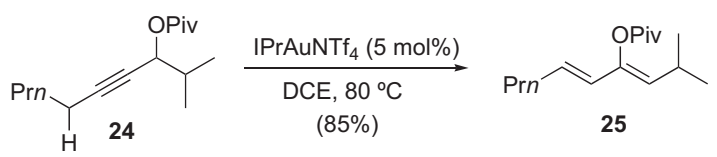

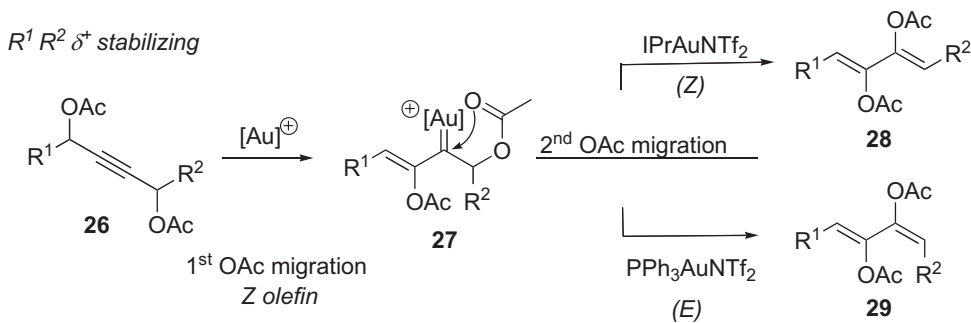

Scheme 7
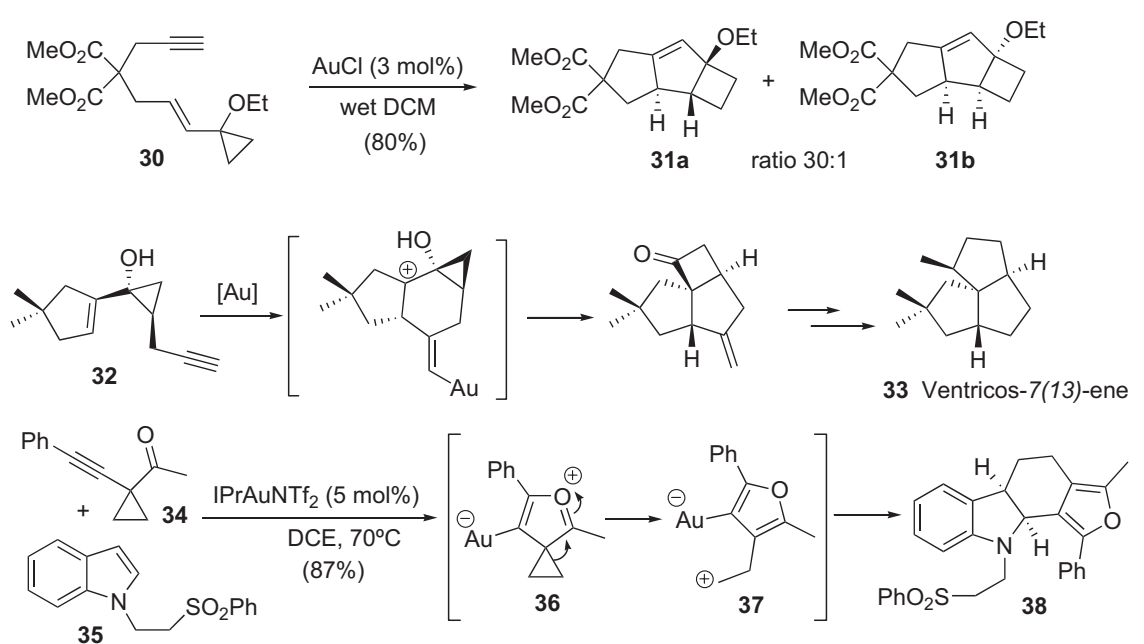

Scheme 8.

teresting biological properties (e.g. Apoptolidinone, Restricticin, Iejimalides, etc...). Our group has recently reported a new $\mathrm{Au}-$ catalyzed tandem 1,2-/1,2-bisacetoxy rearrangement of 1,4-bis-propargyl acetates 26, which provides access to synthetically useful 2,3-bisacetoxy-1,3-dienes in high yields (Scheme 7). ${ }^{[30]}$ Upon careful selection of the electronic and steric features of the substrate, $(1 Z, 3 Z)-28$ or $(1 Z, 3 E$ and $1 E, 3 Z$ )-1,3-dienes 29 can be selectively obtained when IPrAuNTf $f_{2}$ or $\mathrm{PPh}_{3} \mathrm{AuNTf}_{2}$ are employed as catalysts respectively. ${ }^{[31]}$ In our view, a distinct stereocontrol operates for the first $v s$. the second acetate migration. Upon gold activation of the triple bond, the acetoxy group next to groups able to stabilize the developing positive electron density will migrate first, determining the $Z$ stereochemistry of the alkene linked to gold carbenoid to avoid the 1,3-allylic strain between $\mathrm{Au}$ and $\mathrm{R}^{1}$ in the precursor of 27 . The stereochemical outcome of the second acetoxy migration depends on the nature of the catalyst. We demonstrated that IPrAuNTf afforded the $Z$ olefin whereas $\mathrm{PPh}_{3} \mathrm{AuNTf}_{2}$ favored $E$ alkene formation. As in Zhang's case, internal alkynes react here along a 1,2-migration path.

\section{Ring Expansions}

Due to its high strain, cyclopropanes and cyclobutanes present unique reac- tivities, offering considerable utility in organic synthesis. An heteroatom-assisted 1,2-shift triggered by gold has been extensively exploited as shown in Scheme 8. Echavarren and coworkers has successfully combined this reaction mode with a cycloisomerization process in a goldcatalyzed Prins cyclization of enynes 30 affording octahydrocyclobuta[a]pentalene skeletons 31. ${ }^{[32]}$ A remarkable synthetic application of these methodologies has also been recently reported by Toste and co-workers applying a gold-catalyzed ring expansion of cyclopropanols $\mathbf{3 2}$ to the synthesis of the angular triquinane Ventricosene 33 (Scheme 8). ${ }^{[33]}$ Finally, the ring expansion of cyclopropyl ketones such as 34 can be used to generate 1,4-dipoles (37), which upon $[4 \mathrm{C}+2 \mathrm{C}]$ annulation with indoles (35) afford products of high structural complexity such as tetracycle $38 .{ }^{[34]}$

In our group, a new Au-catalyzed homo-Rautenstrauch rearrangement of 1-cyclopropyl propargylic esters $(\mathbf{3 9}, \mathbf{4 0})$ to give 5-, 6- and also 7-membered ring vinyl acetates under mild conditions has been developed (Scheme 9). ${ }^{[35]}$ A key factor in the successful development of this transformation is the presence of a substituent at the cyclopropyl ring able to stabilize the positive electron density developed during the concomitant ring opening process. The almost complete chirality transfer observed in these reactions suggested that gold-stabilized nonclassical carbocations ${ }^{[36]}$ with a certain configurational stability $(\mathbf{4 1}, \mathbf{4 2})$ might be involved, since enantiomerically enriched cyclohexadienyl (43) and cyclopentenyl acetates (44) could be obtained when optically active cyclopropyl units in the starting materials were employed. This observation is in sharp contrast with the chirality transfer observed in the transformations summarized in Scheme 5, where the stereochemical information is transferred from the propargylic position into the final product. Further studies to obtain deeper insight in the nature of these inter-

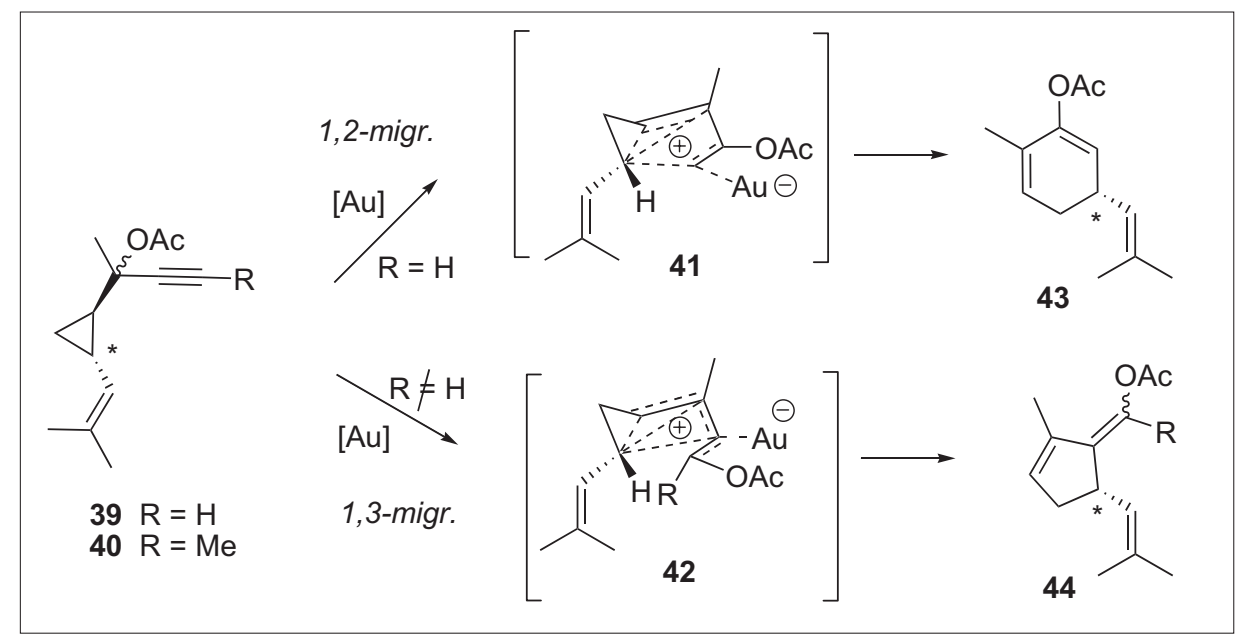

Scheme 9. 
mediates are currently underway and will certainly help to design new stereocontrolled gold-catalyzed processes. ${ }^{[37]}$

\section{Conclusions}

Homogenous catalysis by gold has emerged as a powerful synthetic tool in the past ten years, demystifying the inert character traditionally associated with this noble metal. The distinct coordinating properties of gold and its affinity for unsaturated moieties have contributed to develop a broad array of transformations in which simple starting materials are transformed into highly complex scaffolds. Two of these processes, the rearrangement of propargylic carboxylates and the expansion of cyclopropyl rings have been intensively studied not only for their synthetic potential, but also as mechanistic tools to unravel the key steps involved in the stereocontrol of gold-catalyzed reactions. Building on this knowledge, we will be able to design novel and even more challenging transformations allowing a more standard application of gold catalysis in complex organic synthesis.

\section{Acknowledgements}

Financial support from the Swiss National Science Foundation, Givaudan AG and the Organic Chemistry Institute of the University of Zürich are gratefully acknowledged. I would like to thank Dr. K. Krüger for the critical reading of this manuscript.

Received: February 16, 2010

[1] R. Boyle, 'The Sceptical Chymist: or ChymicoPhysical Doubts and Paradoxes', London, 1661.

[2] For a nice discussion about the origins and historical evolution of alchemy, see A. G. Debus in 'Dictionary of the History of IdeasAlchemy', Ed. P. Philip, Wiener, 1973.

[3] P. L. Bernstein, in 'The Power of Gold: the History of an Obsession', John Wiley \& Sons, New York, 2000.

[4] W. Schwemberger, W. Gordon, Chem. Zentralbl. 1935, 106, 514.

[5] P. G. Gassman, G. R. Meyer, F. J. Williams, J. Am. Chem. Soc. 1972, 94, 7741.

[6] Y. Ito, M. Sawamura, T. Hayashi, J. Am. Chem. Soc. 1986, 108, 6405 .
[7] a) J. A. van Bokhoven, Chimia 2009, 63, 257; b) H. A. Wegner, Chimia 2009, 63, 44.

[8] P. Pyykkö, Angew. Chem., Int. Ed. 2004, 43, 4412

[9] A. Fürstner, P. W. Davies, Angew. Chem., Int. Ed. 2007, 46, 3410.

[10] For a selection of general reviews, see: ref. [9] and also: a) E. Jiménez-Nuñez, A. M. Echavarren, Chem. Rev. 2008, 108, 3326; b) V. Michelet, P. Y. Toullec, J. P. Genêt, Angew. Chem., Int. Ed. 2008, 47, 4268; c) Z. Li, C. Brouwer, C. He, Chem. Rev. 2008, 108, 3239; d) A. S. K. Hashmi, Chem. Rev. 2007, 107, 3180.

[11] a) R. Huettel, H. Forkl, Chem. Ber. 1972, 105, 1; b) N. D. Shapiro, F. D. Toste, Proc. Natl. Acad. Sci. USA 2008, 105, 2779; c) L. P. Liu, B. Xu, M. S. Mashuta, G. B. Hammond, J. Am. Chem. Soc. 2008, 130, 7642; d) A. S. K. Hashmi, A Schuster, F. Rominger, Angew. Chem., Int. Ed. 2009, 48, 8247 .

[12] A rapid survey in Scifinder shows more than $50: 1$ ratio of methodological vs. synthetic developments involving gold.

[13] For a mini-review, see: a) N. Marion, S. P. Nolan, Angew. Chem., Int. Ed. 2007, 46, 2750; b) J. Marco-Contelles, E. Soriano, Chem. Eur. J. 2007, 13, 1350

[14] a) A. Correa, N. Marion, L. Fensterbank, M. Malacria, S. P. Nolan, L. Cavallo, Angew. Chem. Int. Ed. 2008, 47, 718; b) N. Marion, G. Lemière, A. Correa, C. Costabile, R. S. Ramón, X. Moreau, P. de Frémont, R. Dahmane, A. Hours, D. Lesage, J.-C. Tabet, J.-P. Goddard, V. Gandon, L. Cavallo, L. Fensterbank, M. Malacria, S. P. Nolan, Chem. Eur. J. 2009, 15, 3243.

[15] For selected references: a) V. Mamame, T. Gress, H. Krause, A. Fürstner, J. Am. Chem. Soc. 2004, 126, 8654; b) D. J. Gorin, P. Dubé, F. D. Toste, J. Am. Chem. Soc. 2006, 128, 14480; c) N. Marion, P. de Frémont, G. Lemière, E. D. Stevens, L. Fensterbank, M. Malacria, S. P. Nolan, Chem. Commun. 2006, 2048; d) A. Buzas, F. Gagosz, Org. Lett. 2006, 8, 515; e) C. H. M. Amijs, V. López-Carrillo, A. M. Echavarren, Org. Lett. 2007, 9, 4021; f) G. Zhang, L. Zhang, J. Am. Chem. Soc. 2008, 130, 12598 .

[16] For selected references: a) L. Zhang, J. Am. Chem. Soc. 2005, 127, 16804; b) A. Buzas, F. Gagosz, J. Am. Chem. Soc. 2006, 128, 12614; c) S. Wang, L. Zhang, Org. Lett. 2006, 8, 4585.

[17] H. Stickler, J. B. Davis, G. Ohloff, Helv. Chim. Acta 1976, 59, 1328.

[18] a) V. Rautenstrauch, J. Org. Chem. 1984, 49, 950; b) V. Rautenstrauch, U. Burger, P. Wirthner, Chimia 1985, 39, 7

[19] a) K. Miki, K. Ohe, S. Uemura, Tetrahedron Lett. 2003, 44, 2019; b) K. Miki, K. Ohe, S. Uemura, J. Org. Chem. 2003, 68, 8505.

[20] a) E. Mainetti, V. Mouriès, L. Fensterbank, M. Malacria, J. Marco-Contelles, Angew. Chem., Int. Ed. 2002, 41, 2132; b) Y. Harrak,
C. Blaszykowski, M. Bernhard, K. Cariou, E. Mainetti, V. Mouriès, A.-L. Dhimane, L. Fensterbank, M. Malacria, J. Am. Chem. Soc. 2004, 126, 8656

[21] C. A. Witham, P. Mauleón, N. D. Shapiro, B D. Sherry, F. D. Toste, J. Am. Chem. Soc. 2007 $129,5838$.

[22] M. J. Johansson, D. J. Gorin, S. T. Staben, F. D Toste, J. Am. Chem. Soc. 2005, 127, 18002.

[23] N. D. Shapiro, Y. Shi, F. D. Toste, J. Am. Chem. Soc. 2009, 131, 11654.

[24] a) X. Shi, D. J. Gorin, F. D. Toste, J. Am. Chem Soc. 2005, 127, 5802; b) O. Nieto-Faza, C. López, R. Álvarez, A. R. de Lera, J. Am. Chem. Soc. 2006, 128, 2434.

[25] a) A. Fürstner, P. Hannen, Chem. Comm. 2004 22, 2546; b) A. Fürstner, P. Hannen, Chem. Eur. J. 2006, 12, 3006; c) C. Fehr, J. Galindo, Angew. Chem., Int. Ed. 2006, 45, 2901; d) C. Fehr, B. Winter, I. Magpantay, Chem. Eur. J. 2009, 15, 9773.

[26] N. Marion, S. Díez-González, P. de Frémont, A R. Noble, S. P. Nolan, Angew. Chem., Int. Ed. 2006, 45, 3647.

[27] S. Wang, L. Zhang, J. Am. Chem. Soc. 2006 128,8414 .

[28] L. Zhang, S. Wang, J. Am. Chem. Soc. 2006, 128,1442 .

[29] G. Zhang, L. Zhang, J. Am. Chem. Soc. 2008, 130,3740

[30] X. Huang, T. de Haro, C. Nevado, Chem. Eur. J. 2009, 15, 5904.

[31] D. J. Gorin, B. D. Sherry, F. D. Toste, Chem Rev. 2008, 108, 3351.

[32] E. Jiménez-Nuñez, C. K. Claverie, C. NietoOberhuber, A. M. Echavarren, Angew. Chem. Int. Ed. 2006, 45, 5452.

[33] S. G. Sethofer, S. T. Staben, O. Y. Hung, F. D. Toste, Org. Lett. 2008, 10, 4315.

[34] G. Zhang, X. Huang, G. Li, L. Zhang, J. Am. Chem. Soc. 2008, 130, 1814.

[35] a) Y. Zou, D. Garayalde, Q. Wang, C. Nevado, A. Goeke, Angew. Chem., Int. Ed. 2008 47, 10110; b) P. Mauleón, J. L. Krinsky, F. D. Toste, J. Am. Chem. Soc. 2009, 131, 4513.

[36] a) G. Olah, V. P. Reddy, G. K. S. Prakash, Chem. Rev. 1992, 92, 69; b) A. Fürstner, F. Stelzer, H. Szillat, J. Am. Chem. Soc. 2001, 123, 11863; c) A. Fürstner, L. Morency, Angew. Chem., Int. Ed. 2008, 47, 5030.

[37] D. Garayalde, E. Gómez-Bengoa, X. Huang, A Goeke, C. Nevado, J. Am. Chem. Soc. 2010, doi: 10.1021/ja909013j. 